\title{
Diallyl trisulfide-induced prostate cancer cell death is associated with Akt/PKB dephosphorylation mediated by P-p66she
}

\author{
Andzelika Borkowska • Alicja Sielicka-Dudzin • Anna Herman-Antosiewicz • \\ Michal Wozniak · Donatella Fedeli · Giancarlo Falcioni · Jedrzej Antosiewicz
}

Received: 3 May 2011/Accepted: 7 October 2011

(c) The Author(s) 2011. This article is published with open access at Springerlink.com

\begin{abstract}
Purpose P66Shc, an isoform of adaptor proteins, is known to mediate various signals including those leading to apoptosis or cell proliferation. Previously, we have shown that diallyl trisulfide (DATS)-induced prostate cancer cell death was mediated by increased ROS formation. In this study, we investigated the role of p66Shc protein and its serine 36 phosphorylation in DATS induced decrease in prostate cancer cell viability (PC-3).

Methods PC-3 prostate cancer cells were used in this study. Stable cell lines expressing p66ShcS36A or an empty vector have been obtained. Cell viability, concentration of ROS, changes in P-p66Shc and P-Akt and DNA damage were determined.
\end{abstract}

A. Borkowska · A. Sielicka-Dudzin · J. Antosiewicz ( $\square)$ Department of Bioenergetics and Physiology of Exercise, Medical University of Gdańsk, Dębinki 1,

80-211 Gdańsk, Poland

e-mail: jant@amg.gda.pl

\author{
A. Herman-Antosiewicz \\ Department of Medical Chemistry, Medical University \\ of Gdansk, Gdansk, Poland \\ M. Wozniak \\ Department of Molecular Biology, University of Gdansk, \\ Gdansk, Poland \\ D. Fedeli · G. Falcioni \\ Dipartimento di Biologia MCA, Università degli Studi \\ di Camerino, Camerino, Italy \\ J. Antosiewicz \\ Department of Biochemistry, Academy of Physical Education \\ and Sport, Gdansk, Poland
}

Results We observed that DATS treatment increased p66Shc phosphorylation at serine 36. Importantly, the phosphorylation was abolished by JNK inhibitor SP600125. Cells expressing plasmid-encoded variant of p66ShcS36A showed much higher resistance to DATSinduced cells death. In addition to that, we observed that DATS-induced ROS formation was completely abolished in cells expressing the p66ShcS36A variant. Interestingly, SP600125 proved to prevent DATS-induced Akt inactivation. In order to confirm that the observed effect is related to phosphorylation of p66Shc, we performed experiments on a stable cell line expressing p66ShcS36A. In such cells, DATS-induced Akt dephosphorylation was significantly reduced. On the other hand, hydrogen peroxide induced Akt activation in PC-3 cells, which was abrogated in cells expressing p66ShcS36A.

Conclusions Our results uncover a novel signaling pathway with p66Shc being indispensable for DATS-induced inactivation of Akt due to hypophosphorylation.

Keywords Garlic $\cdot$ Oxidative stress $\cdot \mathrm{c}$-jun kinase $\cdot$ Stress

\section{Introduction}

Epidemiological and clinical studies have shown that consumption of garlic and other allium vegetables reduces the risk of prostate cancer [1]. Laboratory data showed that organosulfur compounds (OSCs), such as diallyl disulfide (DADS) and diallyl trisulfide (DATS) among others, are responsible for protective action of allium vegetables [2]. There is increasing evidence that OSCs anticancer activity is related to modulation of signal transduction pathways [3]. Induction of cell cycle arrest and apoptosis by DATS and DADS was shown to be dependent on the generation of 
reactive oxygen species (ROS) [4]. Filomeni et al. [5] observed that DADS increased ROS formation and led to c-jun terminal kinase (JNK)-dependent cancer cell death. They also reported oxidative stress-dependent damage to protein and lipid molecules. Importantly, treatment with spin trap 5,5'-dimethyl-1-pyrroline $\mathrm{N}$-oxide as well as overexpression of the antioxidant enzyme, namely $\mathrm{Cu} / \mathrm{Zn}$ superoxide dismutase, resulted in the inhibition of DADSmediated toxicity via the attenuation of JNK/c-Jun pathway activity. Moreover, treatment with JNK inhibitor I significantly reduced DADS-induced apoptosis [5]. ROS have been shown to activate JNK which in turn could stimulate further ROS formation [6]. In our previous study, we observed that JNK activation leads to ferritin degradation, and consequently an increase in labile iron pool and irondependent ROS formation [7, 8].

One of the proteins phosphorylated by JNK is p66Shc [9], an adaptor protein responsible for life-span regulation and cellular sensitivity to hydrogen peroxide and other cytotoxins. P66Shc is a splice variant of p52Shc/p46Shc, a cytoplasmic signal transducer involved in the transmission of mitogenic signals from tyrosine kinases to RAS. P66Shc has the same modular structure of p52Shc/p46Shc (SH2$\mathrm{CH} 1-\mathrm{PTB})$; however, its N-terminal region $(\mathrm{CH} 2)$ is unique [10]. P66shc undergoes phosphorylation at serine 36 (within $\mathrm{CH} 2$ region) in cell cultures treated with $\mathrm{UV}$ or other oxidative stress inducers, e.g. $\mathrm{H}_{2} \mathrm{O}_{2}$. This kind of phosphorylation seems essential for the proapoptotic activity of p66Shc as fibroblasts p66Shc $-/-$ are resistant to UV- or $\mathrm{H}_{2} \mathrm{O}_{2}$-induced apoptosis. In contrast, increased sensitivity to UV or $\mathrm{H}_{2} \mathrm{O}_{2}$ has been observed in cells overexpressing p66Shc [11-14].

Recently, it has been shown that prostate cancer specimens had higher levels of p66Shc than adjacent noncancerous cells [15]. Moreover, in prostate cancer cell lines, a positive correlation was found between the p66Shc protein level and the cell proliferation [16].

In prostate and breast cancer cells, the p66Shc protein level positively correlates with the activation of extracellular signal-regulated kinases ERK/MAPK activation [16]. Moreover, it has been shown that in prostate cancer specimens both the p66Shc protein level and the ERK/MAPK phoshorylation are elevated [17]. On the other hand, p66Shc reduced the ERK/MAPK activation in different cell types $[14,18,19]$. The negative effect of p66Shc on mitogenic signaling involves competitive inhibition of p52Shc binding to its upstream molecular partners and sequestering Grb2/Sos into a signaling-incompetent complex $[20,21]$.

Akt is an essential serine/threonine kinase whose activation has been detected in various human malignancies. Akt activity is often increased in prostate and breast cancer. Activated Akt protects cells against apoptotic death by phosphorylating proteins such as $\mathrm{BAD}, \mathrm{NF}-\kappa \mathrm{B}$, procaspase- 9 and fork-head transcription family members [22]. Akt has been shown to influence apoptosis through increased degradation of $\mathrm{p} 53$ protein [23]. These and other evidence indicate that Akt plays an important role in tumorigenesis by stimulating cell survival pathways. In addition to that, Akt activity may stimulate prostate cancer progression and invasion via downregulation of the cyclindependent kinase inhibitor, p27 [24, 25]. It was observed that DATS downregulated Akt phosphorylation and it was associated with the degradation of insulin-like growth factor receptor 1 protein as well as with the inhibition of its autophosphorylation [26]. On the other hand, $\mathrm{H}_{2} \mathrm{O}_{2^{-}}$ induced oxidative stress increased Akt activation and importantly this process was impaired in cells devoid of p66Shc [27]. Therefore, we hypothesized that p66Shc might play a role in DATS-induced prostate cancer cell death by modulating the Akt activity and ROS generation.

\section{Materials and methods}

\section{Reagents}

PC-3 cells were purchased from American Type Culture Collection. Tissue culture media were from Gibco Life Technologies (Warsaw, Poland). Antibiotic mixture and fetal bovine serum were from Sigma-Aldrich. 6-Carboxy$2^{\prime}, 7^{\prime}$-dichlorodihydrofluorescein diacetate $\left(\mathrm{H}_{2} \mathrm{DCFDA}\right)$ was from Molecular Probes (Warsaw, Poland). The antibodies against AKT, phospho-(Ser473)-Akt, were from Santa Cruz Biotechnology (Heidelberg, Germany). The antibodies against ERK, P-ERK, were from Cell Signaling Technology, and actin was from Sigma-Aldrich. Ltd (Poznan, Poland). Mouse monoclonal antibody to phosphop66Shc (Ser 36) was from Abcam Inc. DATS was purchased from LKT Laboratories (St. Paul, MN).

\section{Cell culture and transfection}

The PC-3 cells were cultured in F12 K supplemented with $10 \%$ fetal bovine serum and antibiotics. The cells were maintained at $37{ }^{\circ} \mathrm{C}$ in an atmosphere of $95 \%$ air and $5 \%$ $\mathrm{CO}_{2}$. Plasmid encoding mutant p66Shc (p66ShcS36A) was kindly provided by Dr. Toren Finkel [27]. PC-3 cells were transfected with the plasmid encoding p66ShcS36A or an empty pcDNA3.1 vector at $50-60 \%$ confluence using FuGENE HD Transfection Reagent (Roche, Indianapolis, IN). After $24 \mathrm{~h}$ of transfection, cells were treated with DATS and processed for different assays.

PC-3 cell lines stably expressing dominant-negative mutant p66Shc (p66ShcS36A) or an empty pcDNA3.1 vector were obtained by transfection and subsequent 
isolation using the limiting dilutions techniques in the presence of G418 [27].

\section{Comet assay}

The comet assay procedure used to measure the DNAstrand breaks in individual cells was essentially the same as that described previously [28]. In short, cells were suspended in $0.7 \%$ low-melting agarose in PBS and pipetted onto microscope slides pre-coated with a layer of $1 \%$ regular melting agarose. The agarose with the cellular suspension was allowed to set on the pre-coated slides at $4{ }^{\circ} \mathrm{C}$ for $10 \mathrm{~min}$. Subsequently, another top layer of $0.7 \%$ low-melting agarose was added and allowed to set at $4{ }^{\circ} \mathrm{C}$ for $10 \mathrm{~min}$. The slides were then immersed in lysis solution ( $1 \%$ sodium n-lauroyl sarcosinate, $2.5 \mathrm{M} \mathrm{NaCl}, 100 \mathrm{mM}$ $\mathrm{Na}_{2}$ EDTA, $10 \mathrm{mM}$ Tris $\mathrm{HCl} \mathrm{pH} \mathrm{10,1 \%}$ Triton X-100 and $10 \% \mathrm{DMSO}$ ) for $1 \mathrm{~h}$ at $4{ }^{\circ} \mathrm{C}$ in the dark, in order to lyse the embedded cells and to permit DNA unfolding. After incubation in lysis solution, the slides were exposed to alkaline buffer ( $1 \mathrm{mM} \mathrm{Na} 2$ EDTA, $300 \mathrm{mM} \mathrm{NaOH}$ buffer, $\mathrm{pH}>13$ ) for $20 \mathrm{~min}$ to allow DNA unwinding, and then subjected to 20-min electrophoresis at $25 \mathrm{~V}$ in the same alkaline buffer. After electrophoresis, the slides were washed with $0.4 \mathrm{M}$ Tris $\mathrm{HCl}$ buffer ( $\mathrm{pH} 7.5$ ) to neutralize excess alkali and to remove detergents before staining with ethidium bromide $(2 \mu \mathrm{g} / \mathrm{mL})$.

\section{Evaluation of DNA damage}

Cells were examined with an Axioskop 2 plus microscope (Carl Zeiss, Germany) equipped with an excitation filter of $515-560 \mathrm{~nm}$ and a magnification of $\times 20$. Imaging was performed using a specialized analysis system ("Metasystem" Altlussheim, Germany) to determine tail moment (TM), tail intensity (TI), tail length (TL) and \% tail DNA, and all parameters correlated with the degree of DNA damage in the single cell.

Detection of apoptosis

Apoptosis was determined by flow cytometry using the FITC Annexin V Apoptosis Detection Kit I (BD Pharmingen). PC-3 cells $\left(1 \times 10^{5} / \mathrm{mL}\right)$ were seeded in $10-\mathrm{cm}$ plates for $24 \mathrm{~h}$ and then exposed to DATS $(40 \mu \mathrm{g} / \mathrm{mL})$ for $24 \mathrm{~h}$. After this incubation, the cancer cells were washed and resuspended in binding buffer. The cell suspension was then incubated with $5 \mu \mathrm{L}$ of Annexin V-FITC and 2, $5 \mu \mathrm{L}$ of propidium iodide (PI) for $10 \mathrm{~min}$ at room temperature in the dark. Cells were resuspended in binding buffer again. The population of Annexin V-positive cells was evaluated by Coulter Epics XL Flow Cytometer.
ROS assay

Intracellular ROS generation was measured by flow cytometric monitoring of oxidation of $\mathrm{H}_{2}$ DCFDA, which is cleaved by nonspecific cellular esterases and oxidized in the presence of peroxides as well as iron. $2 \times 10^{5}$ cells were plated, allowed to attach overnight and exposed to $40 \mu \mathrm{M}$ DATS for $4 \mathrm{~h}$. Subsequently, the cells were stained with $5 \mu \mathrm{mol} / \mathrm{L} \mathrm{H}_{2}$ DCFDA for $30 \mathrm{~min}$ at $37{ }^{\circ} \mathrm{C}$ in complete medium. The cells were collected by trypsynization and centrifugation, washed two times with PBS and kept on ice in the dark, and then fluorescence was assayed using a Coulter Epics XL Flow Cytometer. Fluorescence of unstained cells was also measured in order to subtract the background fluorescence.

\section{Immunoblotting}

The cells were treated with DATS as described above. Both floating and attached cells were collected; washed in PBS; resuspended in a lysis solution containing $50 \mathrm{mmol} / \mathrm{L}$ Tris$\mathrm{HCl}$ (pH 7.5), $150 \mathrm{mmol} / \mathrm{L} \mathrm{NaCl}, 1 \%$ Triton $\mathrm{X}-100,0.1 \%$ SDS; and incubated for $40 \mathrm{~min}$ on ice with gentle shaking. The cell lysate was cleared by the centrifugation at $16.000 \mathrm{~g}$ for $20 \mathrm{~min}$. Lysate proteins were resolved in 10-12\% SDS-PAGE and subjected to immunoblotting as described previously [7]. Changes in protein level was assessed by densitometric scanning of the bands and corrected for $\beta$-actin loading control.

\section{Results}

Expression of p66ShcS36A protects PC-3 cells against DATS-induced death

First of all, we observed that in DATS-treated cells, the p66Shc phosphorylation at serine 36 increase continuously until $12 \mathrm{~h}$ of treatment (Fig. 1a). We used chemical inhibitors to establish which kinases are responsible for serine 36 phosphorylation of p66Shc. As shown in Fig. 1b pretreatment of PC-3 cells with SP600125, a JNK inhibitor almost completely abolished the DATS-induced p66Shc phosphorylation at serine 36 . These data indicate that JNK kinases phosphorylate p66Shc in PC-3 cells. To find out if this phosphorylation plays a role in DATS- induced cell death, we generated PC-3 cell line stably transfected with an empty vector or plasmid encoding p66ShcS36A. This mutant cannot be phosphorylated at serine 36 , and therefore, the proapoptotic activity of p66Shc should be suppressed [29]. As shown in Fig. 1c, position-36 mutant of p66Shc migrated with a faster mobility what is in agreement with previously published data [27]. Moreover, in the 
A

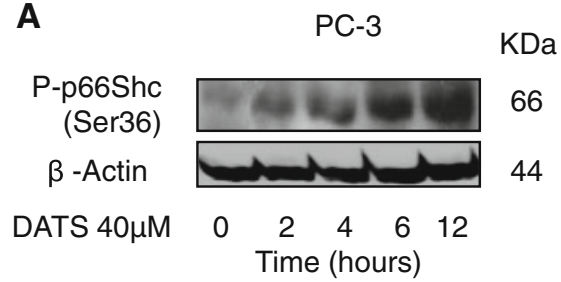

B

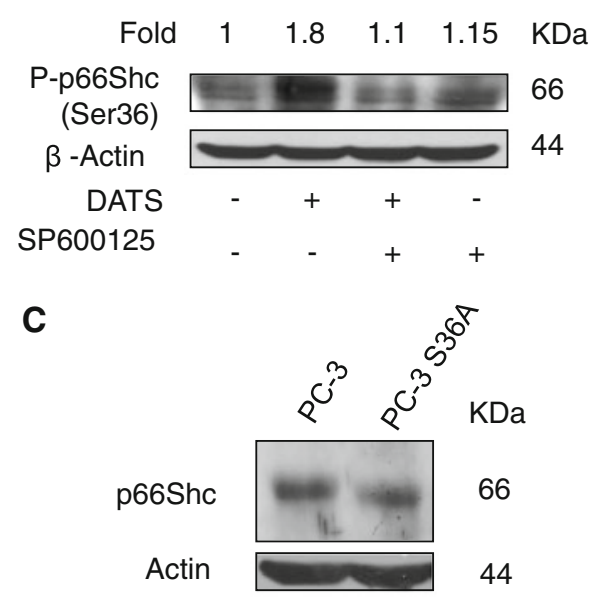

D

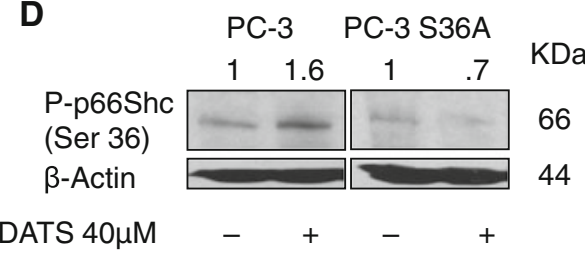

Fig. 1 DATS-induced serine 36 phosphorylation is JNK dependent. a Immunoblotting for P-p66Shc using lysates of PC-3 cells treated with DMSO (control) or 40- $\mu$ M DATS for the indicated time periods. b Immunoblotting for P-p66Shc using lysates of PC-3 cells treated for $4 \mathrm{~h}$ with DMSO (control) or 40- $\mu \mathrm{M}$ DATS in the absence or presence of $20-\mu \mathrm{M}$ SP600125 ( $1 \mathrm{~h}$ pretreatment). The numbers on top of the immunoreactive bands represent change in levels relative to DMSOtreated control. The data shown are from one of three independent experiments. c Immunoblotting for p66Shc using lysates from PC-3 cells stably expressing empty vector or p66ShcS36A. d Immunoblotting for P-p66Shc using lysates from PC-3 cells stably expressing empty vector or p66ShcS36A treated $2 \mathrm{~h}$ with DMSO (control) or $40-\mu \mathrm{M}$ DATS. The data shown are from one of three independent experiments

cells expressing p66ShcS36A, DATS treatment did not induced p66Shc phosphorylation (Fig. 1d). Cells expressing p66ShcS36A are much more resistant to DATSinduced cell death (Fig. 2a, b). These data indicate that DATS-induced cell death is mediated by p66Shc and that it is associated with its phosphorylation at serine 36 . Assessment of DNA damage was carried out using the comet assay. A percentage DNA in tail that is a valid marker of DNA breakage [30]. DATS induced an increase in DNA tail content in PC-3 cells but slightly decreased it in cells expressing p66ShcS36A; however, the values did not reach statistical significance (data not shown). Flow cytometry analysis, using FITC Annexin V and PI to detect apoptosis, showed that of PC-3 cells expressing empty vector $24 \mathrm{~h}$ of DATS treatment induced increase percentage of apoptotic cells by 12.9 , while in PC-3 S36A cells only by 4.5 (Fig. 2b).

DATS-induced ERK phosphorylation is affected in cells expressing p66ShcS36A

Previously, it has been shown that DATS-induced prostate cancer cell death was partially reversed by the inhibition of ERK1/2 [31]. Therefore, the next goal of this study was to establish whether p66Shc plays a role in DATS-induced ERK1/2 phosphorylation. Activation of ERK1/2 was evident as early as $0.25 \mathrm{~h}$ after DATS treatment, reached its maximum after $0.5 \mathrm{~h}$ and then decreased but it was still elevated after $6 \mathrm{~h}$ in cells expressing the empty vector (Fig. 3a). On the other hand, the expression of ERK1/2 protein was not altered by DATS treatment. In cells transfected with plasmid encoding p66ShcS36A, DATSinduced ERK phosphorylation was almost completely abolished (Fig. 3b). These data indicate that P-p66Shc is involved in DATS-induced modulation of ERK activity.

DATS-induced S473 dephosphorylation of Akt is inhibited in cells expressing p66ShcS36A

As shown previously, DATS-induced cell death is accompanied by a decrease in Akt activity [26]. Here, we confirmed the observation that DATS induces Akt dephosphorylation at serine 473, (position essential for its activity) in time-dependent manner (Fig. 4a). However, in cells that are stable or transiently (not shown) transfected with plasmid encoding p66ShcS36A, the phosphorylation maintained at a high level after DATS treatment (Fig. 4b). As previously reported, p66Shc is essential for $\mathrm{H}_{2} \mathrm{O}_{2}$ induced Akt phosphorylation rather than its dephosphorylation [27], thus we repeated this experiment in our model. As shown in Fig. 4c, $\mathrm{H}_{2} \mathrm{O}_{2}$-induced Akt activation in PC-3 cells transfected with an empty vector; however, in p66ShcS36Aexpressing cells such activation was not observed. Altogether, these data indicate that the phosphorylation of p66Shc at serine 36 in PC-3 cells is necessary for DATSinduced Akt dephosphorylation and $\mathrm{H}_{2} \mathrm{O}_{2}$-induced AKT activation. As described above, the JNK kinases are responsible for p66Shc phosphorylation, and therefore, we reasoned that inhibition of JNK by SP600125 should affect Akt phosphorylation in cells treated with DATS or $\mathrm{H}_{2} \mathrm{O}_{2}$. In fact, we observed that $20-\mu \mathrm{M}$ SP600125 reduced DATSinduced Akt dephosphorylation, and $\mathrm{H}_{2} \mathrm{O}_{2}$ induced the Akt phosphorylation (Fig. 4d). 
A
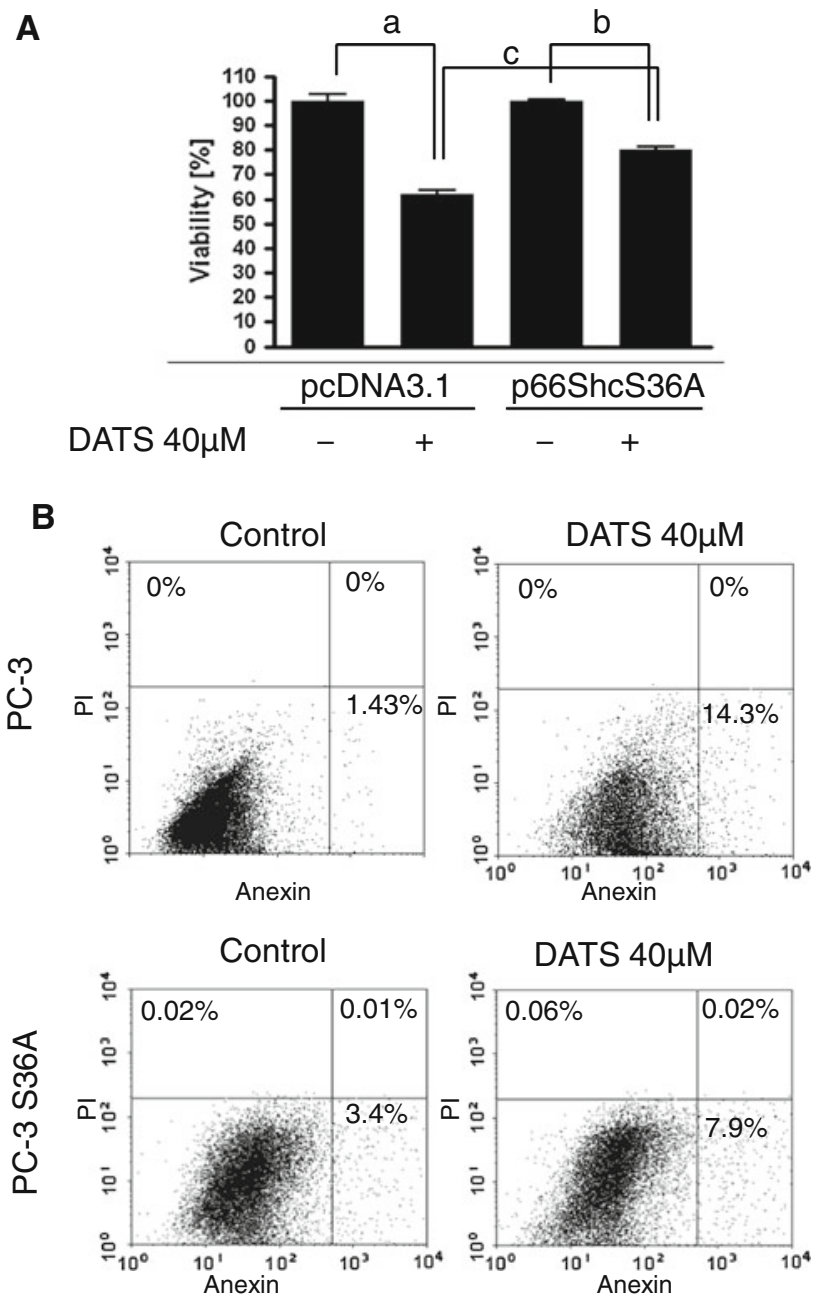

Fig. 2 Expression of dominant-negative p66ShcS36A protects PC-3 cells against DATS-induced death. a Survival of PC-3 cells stably expressing empty vector or p66ShcS36A following a 24-h treatment with DMSO (control) or $40-\mu \mathrm{M}$ DATS as determined by sulforhodamine B assay. Similar results were observed in three independent experiments. Data are mean $\pm \mathrm{SE}(n=5) ; a, b p<0.05$ significantly different compared with respective DMSO-treated control; $c$ significantly different compared with respective DATS-treated cells by oneway ANOVA followed by Dunnett's test. b Flow cytometric analysis of annexin V-FITC staining of PC-3 and PC-3 S36A cells treated with DMSO or $40-\mu \mathrm{M}$ DATS for $24 \mathrm{~h}$

DATS-induced ROS formation was attenuated in cells expressing p66ShcS36A

DATS and many other chemopreventive compounds have been shown to induce cancer cell death by increasing ROS formation [32]. In addition, one of the well-documented proapoptotic actions of p66Shc is the increase in ROS formation. Here, we wanted to confirm our earlier observation that DATS-induced ROS formation in prostate cancer cell is mediated by p66Shc[33]. As shown in Fig. 5a, DATS-induced ROS formation in cells stably transfected with an empty vector, thus confirming our
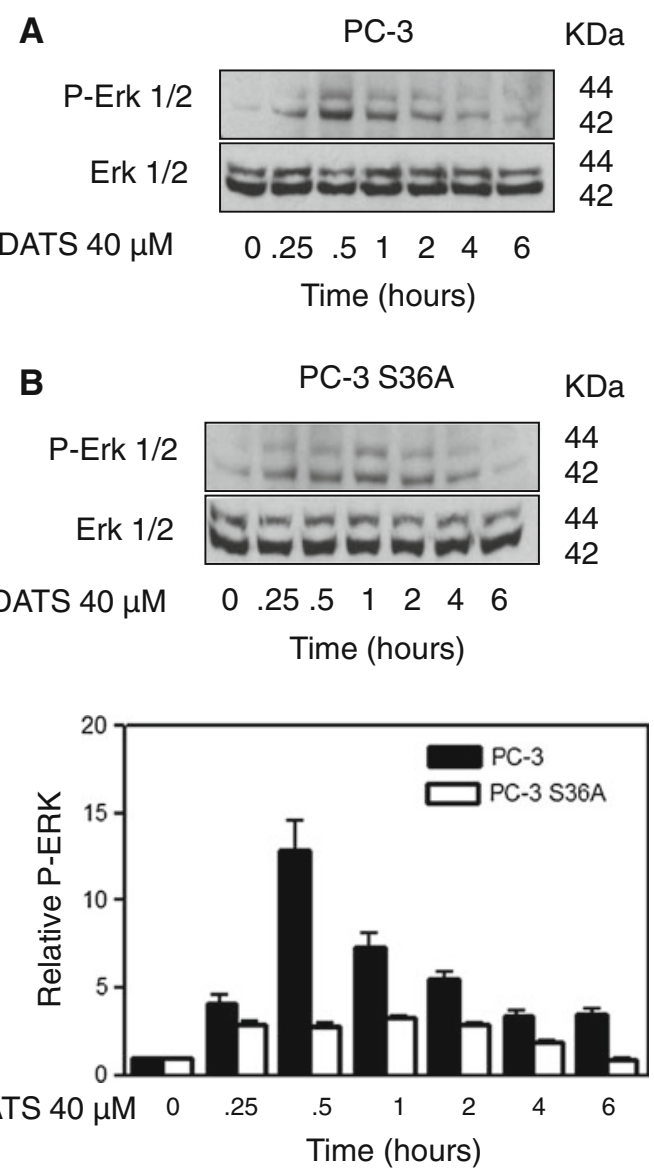

Fig. 3 Expression of dominant-negative p66ShcS36A diminished DATS-induced ERK phosphorylation. Immunoblotting for phosphoERK1/2 (P-ERK1/2) using lysate of (a) PC-3 cells stably expressing empty vector or (b) p66ShcS36A, following a treatment with DMSO or $40-\mu \mathrm{M}$ DATS for the indicated time periods. The blots were stripped and reprobed with anti-ERK1/2. Immunoblotting for each protein was done at least three times using independently prepared lysates, and the results were similar. The bar graph represents averaged data (means $\pm \mathrm{SE}$ ) expressed as fold change over DMSOtreated control

earlier observation. On the other hand, such an increase was not observed in cells expressing p66ShcS36A (Fig. 5b). Interestingly, when basal DCF fluorescences are compared between PC-3 cells expressing empty vector and PC-3 S36A cells, in later, it is consistently higher. Possibly this is due to the difference in cell size as PC-3 S36A are bigger, thus able to accumulate more DCF. Certainly, this method is not appropriate to compare ROS formation in these two cell lines.

\section{Discussion}

An adaptor protein p66Shc has been implicated in cell death induced by hydrogen peroxide among others; however, the molecular mechanism of this action is not fully 
A

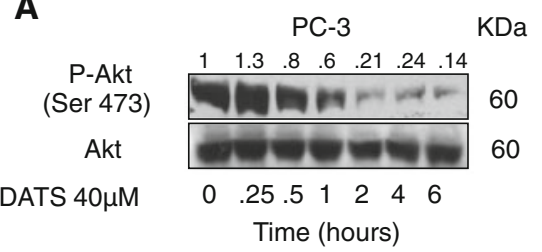

C
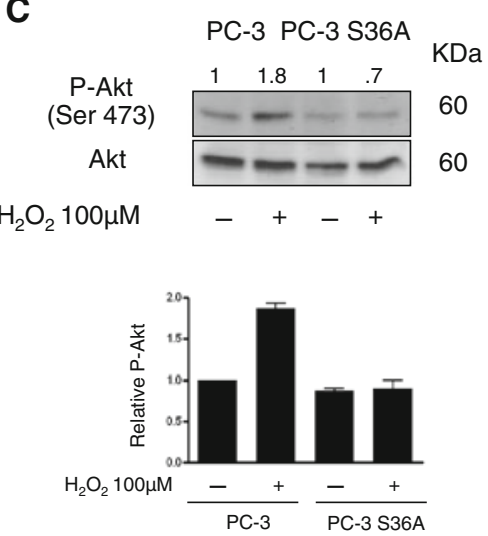

B

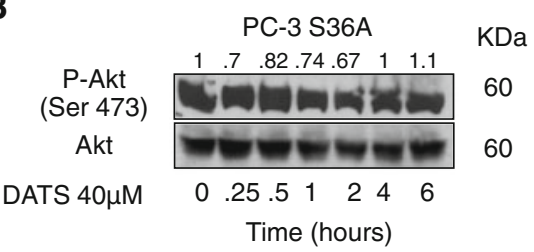

D

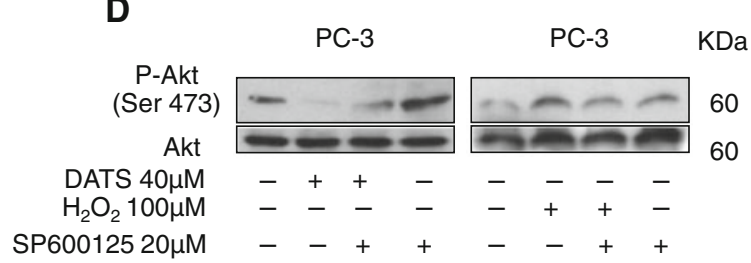

DATS $40 \mu \mathrm{M}$

$\mathrm{H}_{2} \mathrm{O}_{2} 100 \mu \mathrm{M}$

$\mathrm{SP} 60012520 \mu \mathrm{M}$

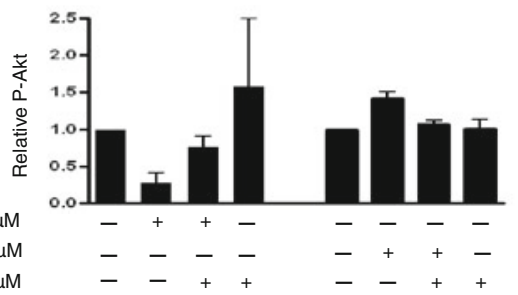

Fig. 4 Expression of dominant-negative p66ShcS36A protects against DATS-induced Akt inactivation and $\mathrm{H}_{2} \mathrm{O}_{2}$-induced Akt activation. Immunoblotting for Akt and phospho-Akt using lysate of (a) PC-3 cells stably expressing empty vector or (b) p66ShcS36A, following treatment with DMSO or 40- $\mu$ M DATS for the indicated time periods. The blots were stripped and reprobed with anti-Akt antibody. The numbers on top of the immunoreactive bands represent change in levels relative to DMSO-treated control. c Immunoblotting for Akt and phospho-Akt using lysate from PC-3 cells stably expressing an empty vector or p66ShcS36A, following the treatment with PBS or $-100 \mu \mathrm{M} \mathrm{H} \mathrm{H}_{2} \mathrm{O}_{2}$ for $1 \mathrm{~h}$. These experiments were

understood. Here, we provide data for new proapoptotic function of p66Shc in DATS-induced PC-3 cell death. Our results indicate that when phosphorylated at serine 36, p66Shc mediates DATS-induced Akt dephosphorylation. Akt protects cells against apoptosis by increasing the phosphorylation of proapoptotic protein BAD and its further degradation, inactivating ASK1, stimulating p53 degradation etc. In addition to that, Akt signaling pathways are frequently activated in cancer cells, and therefore, they are prime targets for cancer therapy [34]. Previously reported DATS-induced cell death is associated with Akt dephosphorylation in prostate cancer cell. Moreover, cells overexpressing constitutively active Akt show a much higher resistance to DATS-induced cell death [26]. Our data show that in cells transfected with a plasmid encoding p66ShcS36A, variant that cannot be phosphorylated at serine 36, DATS-induced Akt dephosphorylation is suppressed. Interestingly, in PC-12 cells, $\mathrm{H}_{2} \mathrm{O}_{2}$-induced Akt activation was p66Shc dependent. In PC-12 cells that expressed p66ShcS36A, $\mathrm{H}_{2} \mathrm{O}_{2}$ treatment did not induce Akt activation [27]. In order to verify whether these performed at least three times,yielding the same results. The blot was stripped and re-probed with anti-Akt. The bar graph represents averaged data (means $\pm \mathrm{SE}$ ) expressed as fold change over DMSOtreated control. d Immunoblotting for Akt and phospho-Akt using lysate from PC-3 cells following an treatment with 40- $\mu$ M DATS for $4 \mathrm{~h}$ or $100 \mu \mathrm{M} \mathrm{H} \mathrm{H}_{2} \mathrm{O}_{2}$ for $1 \mathrm{~h}$ with and without pretreatment with 20- $\mu \mathrm{M}$ SP600125. These experiments were performed at least three times,yielding the same results. The bar graph represents averaged data (means $\pm \mathrm{SE}$ ) expressed as fold change over DMSO or PBStreated control

contradictory effects of p66Shc on Akt activity are cellspecific or rather they are the effect of different stressors $\left(\mathrm{H}_{2} \mathrm{O}_{2}\right.$ or DATS), the PC-3 cells were also treated with $\mathrm{H}_{2} \mathrm{O}_{2}$. Interestingly, it was observed that similarly to PC-12 cells, $\mathrm{H}_{2} \mathrm{O}_{2}$ induced Akt activation in PC-3 cells but such effect was strongly reduced in cells expressing p66ShcS36A. These data indicate that p66Shc is indispensable for Akt inactivation or activation in DATS- or $\mathrm{H}_{2} \mathrm{O}_{2}$-treated PC-3 cells, respectively. While this study was still under way, a paper supporting our data was published, showing that B-cell-receptor-mediated Akt phosphorylation at serine 473 was abrogated in cells overexpressing p66Shc [35]. Altogether, our data as well as the data reported by others researches indicate that p66Shc if phosphorylated at serine 36 leads to Akt inactivation and cell death. Moreover, contradictory effects of P-p66Shc on Akt phosphorylation after treatment with DATS or $\mathrm{H}_{2} \mathrm{O}_{2}$ indicates that despite p66Shc there are other signaling molecules involved in this process. The exact mechanism of p66Shc-mediated Akt inactivation or activation still remains to be determined. Akt activation requires the 


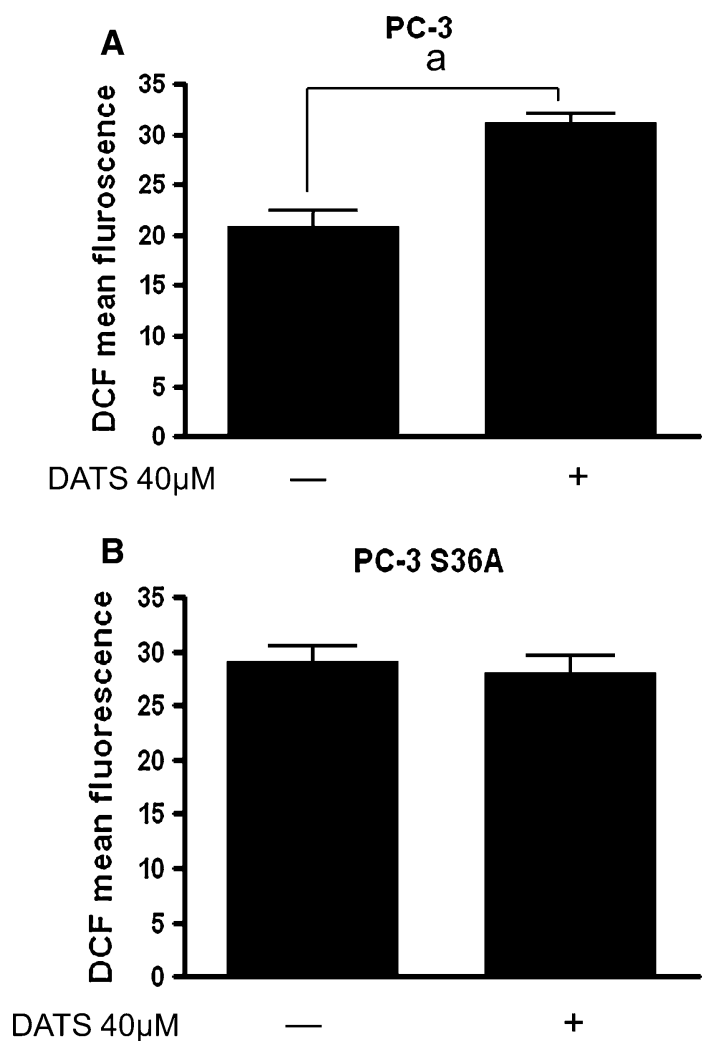

Fig. 5 DATS-induced ROS formation is p66Shc dependent. a Mean DCF fluorescence in PC-3 cultures stably expressing an empty vector treated for $4 \mathrm{~h}$ with $40 \mu \mathrm{mol} / \mathrm{L}$ DATS. Columns, mean $(n=3)$; bars, SE $a, p<0.05$, significantly different as compared with DMSOtreated control followed by $t$ test. b Mean DCF fluorescence in PC-3 cultures stably expressing p66ShcS36A treated for $4 \mathrm{~h}$ with $40 \mu \mathrm{mol} / \mathrm{L}$ DATS. The experiments were performed at least three times, yielding the same results

phosphorylation of Thr 308 and Ser 473 by phosphoinositide-dependent kinase 1 (PDK1) and rictor-mTOR complex, respectively [36]. Whether p66Shc influences substrate specificity or activity of rictor-mTOR complex remains to be determined.

There have been several reports demonstrating that p66Shc is phosphorylated at serine 36 by different kinases. Dependent on the cellular context and on identity of the stimulus, either ERK1/2, JNK, p38 or PKC are responsible for the phosphorylation of p66Shc at S36 [9, 20, 37-39]. In order to check which kinase phosphorylates serine 36 of p66Shc in PC-3 cells, chemical inhibitors were used and the results indicates that JNK is the one responsible for this modification as SP600125 almost completely abolished the phosphorylation. Therefore, it can be expected that SP600125 suppressing p66Shc phosphorylation at serine 36 will also affect DATS-induced Akt inactivation. In fact, a higher degree of Akt phosphorylation at serine 473 was observed in SP600125 and DATS treatment when compared to DATS only treatment. Persistent JNK activation has been shown to induce apoptosis in different cellular models. In addition, JNK inhibition has been shown to reduce cancer cell death induced diallyl disulfide (DADS) or DATS $[5,31]$. Therefore, it can be speculated that JNK mediates DATS-induced prostate cancer cells death at least partially via phosphorylation of p66Shc at serine 36 .

The proapoptotic function of p66Shc has also been related to this protein's ability to stimulate ROS formation. It has been shown that p66Shc is able to associate with the mitochondrial respiratory chain and transfers electrons from cytochrome $\mathrm{c}$ to oxygen molecule, thus generating superoxide anion [40]. In our previous reports, we have shown that DATS-induced prostate cancer cell death was associated with increased ROS formation. Antioxidants like EUK-134 or catalase overexpression significantly protected cells from DATS-induced cell death [41]. Data presented here indicate that DATS-induced ROS formation in PC-3 cells is completely abrogated in cells expressing p66ShcS36A. Thus, it is also possible that cells expressing p66ShcS36A are more resistant to DATS toxicity because of lower ROS formation. In addition, as we have shown previously DATS-induced ROS formation is JNK-dependent [7]. JNK-dependent ROS formation was also demonstrated in other cellular models $[6,8]$. Here, we demonstrated that p66Shc phosphorylation at serine 36 is JNK dependent in DATS-treated cells. Therefore, we suggest that JNK-dependent ROS formation could be associated with the proposed p66Shc phosphorylation. However, more studies are needed to confirm these observations. Increase level of p66Shc has been detected in prostate and breast cancer cells, which in light of our study, may indicate the protein as a potential target for chemotherapy with DATS and possibly other drugs.

Acknowledgments This study was founded by grant from Polish Ministry of Science and Higher Education NN301469838. We thank Janusz Springer and Narcyz Knap for language assistance; Dr Toren Finkel from National Heart, Lung and Blood Institute Bethesda for the generous gift of plasmid encoding mutant of p66Shc.

Open Access This article is distributed under the terms of the Creative Commons Attribution Noncommercial License which permits any noncommercial use, distribution, and reproduction in any medium, provided the original author(s) and source are credited.

\section{References}

1. Hsing AW, Chokkalingam AP, Gao YT, Madigan MP, Deng J, Gridley G, Fraumeni JF Jr (2002) Allium vegetables and risk of prostate cancer: a population-based study. J Natl Cancer Inst 94:1648-1651

2. Powolny AA, Singh SV (2008) Multitargeted prevention and therapy of cancer by diallyl trisulfide and related Allium vegetable-derived organosulfur compounds. Cancer Lett 269:305-314

3. Shukla Y, Kalra N (2007) Cancer chemoprevention with garlic and its constituents. Cancer Lett 247:167-181 
4. Herman-Antosiewicz A, Singh SV (2004) Signal transduction pathways leading to cell cycle arrest and apoptosis induction in cancer cells by Allium vegetable-derived organosulfur compounds: a review. Mutat Res 555:121-131

5. Filomeni G, Aquilano K, Rotilio G, Ciriolo MR (2003) Reactive oxygen species-dependent c-Jun NH2-terminal kinase/c-Jun signaling cascade mediates neuroblastoma cell death induced by diallyl disulfide. Cancer Res 63:5940-5949

6. Ventura JJ, Cogswell P, Flavell RA, Baldwin AS Jr, Davis RJ (2004) JNK potentiates TNF-stimulated necrosis by increasing the production of cytotoxic reactive oxygen species. Genes Dev 18:2905-2915

7. Antosiewicz J, Herman-Antosiewicz A, Marynowski SW, Singh SV (2006) c-Jun $\mathrm{NH}(2)$-terminal kinase signaling axis regulates diallyl trisulfide-induced generation of reactive oxygen species and cell cycle arrest in human prostate cancer cells. Cancer Res 66:5379-5386

8. Antosiewicz J, Ziolkowski W, Kaczor JJ, Herman-Antosiewicz A (2007) Tumor necrosis factor-alpha-induced reactive oxygen species formation is mediated by JNK1-dependent ferritin degradation and elevation of labile iron pool. Free Radic Biol Med 43:265-270

9. Le S, Connors TJ, Maroney AC (2001) c-Jun N-terminal kinase specifically phosphorylates p66ShcA at serine 36 in response to ultraviolet irradiation. J Biol Chem 276:48332-48336

10. Bonfini L, Migliaccio E, Pelicci G, Lanfrancone L, Pelicci PG (1996) Not all Shc's roads lead to Ras. Trends Biochem Sci 21:257-261

11. Pellegrini M, Baldari CT (2009) Apoptosis and oxidative stressrelated diseases: the p66Shc connection. Curr Mol Med 9:392-398

12. Pellegrini M, Finetti F, Petronilli V, Ulivieri C, Giusti F, Lupetti P, Giorgio M, Pelicci PG, Bernardi P, Baldari CT (2007) p66SHC promotes $\mathrm{T}$ cell apoptosis by inducing mitochondrial dysfunction and impaired Ca2 + homeostasis. Cell Death Differ 14:338-347

13. Pellegrini M, Pacini S, Baldari CT (2005) p66SHC: the apoptotic side of Shc proteins. Apoptosis 10:13-18

14. Trinei M, Giorgio M, Cicalese A, Barozzi S, Ventura A, Migliaccio E, Milia E, Padura IM, Raker VA, Maccarana M, Petronilli V, Minucci S, Bernardi P, Lanfrancone L, Pelicci PG (2002) A p53-p66Shc signalling pathway controls intracellular redox status, levels of oxidation-damaged DNA and oxidative stressinduced apoptosis. Oncogene 21:3872-3878

15. Lee MS, Igawa T, Chen SJ, Van Bemmel D, Lin JS, Lin FF, Johansson SL, Christman JK, Lin MF (2004) p66Shc protein is upregulated by steroid hormones in hormone-sensitive cancer cells and in primary prostate carcinomas. Int $\mathrm{J}$ Cancer 108:672-678

16. Veeramani S, Igawa T, Yuan TC, Lin FF, Lee MS, Lin JS, Johansson SL, Lin MF (2005) Expression of p66(Shc) protein correlates with proliferation of human prostate cancer cells. Oncogene 24:7203-7212

17. Gioeli D, Mandell JW, Petroni GR, Frierson HF Jr, Weber MJ (1999) Activation of mitogen-activated protein kinase associated with prostate cancer progression. Cancer Res 59:279-284

18. Migliaccio E, Giorgio M, Mele S, Pelicci G, Reboldi P, Pandolfi PP, Lanfrancone L, Pelicci PG (1999) The p66shc adaptor protein controls oxidative stress response and life span in mammals. Nature 402:309-313

19. Andoh T, Lee SY, Chiueh CC (2000) Preconditioning regulation of bcl-2 and p66shc by human NOS1 enhances tolerance to oxidative stress. Faseb J 14:2144-2146

20. Okada S, Kao AW, Ceresa BP, Blaikie P, Margolis B, Pessin JE (1997) The 66-kDa Shc isoform is a negative regulator of the epidermal growth factor-stimulated mitogen-activated protein kinase pathway. J Biol Chem 272:28042-28049
21. Pacini S, Pellegrini M, Migliaccio E, Patrussi L, Ulivieri C, Ventura A, Carraro F, Naldini A, Lanfrancone L, Pelicci P, Baldari CT (2004) p66SHC promotes apoptosis and antagonizes mitogenic signaling in T cells. Mol Cell Biol 24:1747-1757

22. Nicholson KM, Anderson NG (2002) The protein kinase B/Akt signalling pathway in human malignancy. Cell Signal 14:381-395

23. Ogawara $Y$, Kishishita S, Obata T, Isazawa Y, Suzuki T, Tanaka K, Masuyama N, Gotoh Y (2002) Akt enhances Mdm2-mediated ubiquitination and degradation of p53. J Biol Chem 277:2184321850

24. Shukla S, Maclennan GT, Hartman DJ, Fu P, Resnick MI, Gupta S (2007) Activation of PI3 K-Akt signaling pathway promotes prostate cancer cell invasion. Int J Cancer 121:1424-1432

25. Graff JR, Konicek BW, McNulty AM, Wang Z, Houck K, Allen S, Paul JD, Hbaiu A, Goode RG, Sandusky GE, Vessella RL, Neubauer BL (2000) Increased AKT activity contributes to prostate cancer progression by dramatically accelerating prostate tumor growth and diminishing p27Kip1 expression. J Biol Chem 275:24500-24505

26. Xiao D, Singh SV (2006) Diallyl trisulfide, a constituent of processed garlic, inactivates Akt to trigger mitochondrial translocation of BAD and caspase-mediated apoptosis in human prostate cancer cells. Carcinogenesis 27:533-540

27. Nemoto S, Finkel T (2002) Redox regulation of forkhead proteins through a p66shc-dependent signaling pathway. Science 295: $2450-2452$

28. Santocono M, Zurria M, Berrettini M, Fedeli D, Falcioni G (2007) Lutein, zeaxanthin and astaxanthin protect against DNA damage in SK-N-SH human neuroblastoma cells induced by reactive nitrogen species. J Photochem Photobiol B 88:1-10

29. Migliaccio E, Giorgio M, Pelicci PG (2006) Apoptosis and aging: role of p66Shc redox protein. Antioxid Redox Signal 8:600-608

30. Ho E, Ames BN (2002) Low intracellular zinc induces oxidative DNA damage, disrupts p53, NFkappa B, and AP1 DNA binding, and affects DNA repair in a rat glioma cell line. Proc Natl Acad Sci USA 99:16770-16775

31. Xiao D, Choi S, Johnson DE, Vogel VG, Johnson CS, Trump DL, Lee YJ, Singh SV (2004) Diallyl trisulfide-induced apoptosis in human prostate cancer cells involves c-Jun $\mathrm{N}$-terminal kinase and extracellular-signal regulated kinase-mediated phosphorylation of Bcl-2. Oncogene 23:5594-5606

32. Antosiewicz J, Ziolkowski W, Kar S, Powolny AA, Singh SV (2008) Role of reactive oxygen intermediates in cellular responses to dietary cancer chemopreventive agents. Planta Med 74:1570-1579

33. Borkowska A, Sielicka-Dudzin A, Herman-Antosiewicz A, Halon M, Wozniak M, Antosiewicz J (2011) P66Shc mediated ferritin degradation-A novel mechanism of ROS formation. Free Radic Biol Med 51:658-663

34. Klein S, Levitzki A (2009) Targeting the EGFR and the PKB pathway in cancer. Curr Opin Cell Biol 21:185-193

35. Capitani N, Lucherini OM, Sozzi E, Ferro M, Giommoni N, Finetti F, De Falco G, Cencini E, Raspadori D, Pelicci PG, Lauria F, Forconi F, Baldari CT (2010) Impaired expression of p66Shc, a novel regulator of B-cell survival, in chronic lymphocytic leukemia. Blood 115:3726-3736

36. Sarbassov DD, Guertin DA, Ali SM, Sabatini DM (2005) Phosphorylation and regulation of $\mathrm{Akt} / \mathrm{PKB}$ by the rictor-mTOR complex. Science 307:1098-1101

37. Foschi M, Franchi F, Han J, La Villa G, Sorokin A (2001) Endothelin-1 induces serine phosphorylation of the adaptor protein p66Shc and its association with 14-3-3 protein in glomerular mesangial cells. J Biol Chem 276:26640-26647

38. Yang CP, Horwitz SB (2002) Distinct mechanisms of taxolinduced serine phosphorylation of the $66-\mathrm{kDa}$ Shc isoform in A549 and RAW 264.7 cells. Biochim Biophys Acta 1590:76-83 
39. Pinton P, Rimessi A, Marchi S, Orsini F, Migliaccio E, Giorgio M, Contursi C, Minucci S, Mantovani F, Wieckowski MR, Del Sal G, Pelicci PG, Rizzuto R (2007) Protein kinase C beta and prolyl isomerase 1 regulate mitochondrial effects of the life-span determinant p66Shc. Science 315:659-663

40. Giorgio M, Migliaccio E, Orsini F, Paolucci D, Moroni M, Contursi C, Pelliccia G, Luzi L, Minucci S, Marcaccio M, Pinton P, Rizzuto R, Bernardi P, Paolucci F, Pelicci PG (2005) Electron transfer between cytochrome $\mathrm{c}$ and $\mathrm{p} 66 \mathrm{Shc}$ generates reactive oxygen species that trigger mitochondrial apoptosis. Cell 122:221-233

41. Xiao D, Herman-Antosiewicz A, Antosiewicz J, Xiao H, Brisson M, Lazo JS, Singh SV (2005) Diallyl trisulfide-induced G(2)-M phase cell cycle arrest in human prostate cancer cells is caused by reactive oxygen species-dependent destruction and hyperphosphorylation of Cdc 25 C. Oncogene 24:6256-6268 